\title{
Improvement of Construction Project Management Processes
}

\author{
Joanicjusz Nazarko \\ Editor \\ Editorial \\ Available online July 12, 2017
}

The common denominator of the five papers published in the current edition of the Journal of Engineering, Project, and Production Management is the improvement of construction project management processes for effective use of resources. Execution of proper project management processes is widely recognized as a key success factor influencing likelihood of project success (Alleman, 2014). It is noticeable that four out of five papers in this issue of the Journal are authored or co-authored by Iranian researchers from the same Institute but their conclusions bear importance that cannot be limited to the authors' region.

Two papers contribute to the understanding of issues related to the concepts of Constructability, Operability and Maintainability (COM) in construction projects. The third paper focuses on using data mining techniques to develop knowledge management in organizations. The next paper examines interdependency of value for money and ex-post performance indicators of public private partnership projects. The remaining paper concentrates on the research trends in the field of Integrated Project Delivery (IPD) approach to construction projects.

Paper by N. Kordestani Ghaleenoe et al. of Mehralborz Institute of Higher Education (Tehran, Iran) and Abu Dhabi University (UAE) reviews and analyses scientific literature on the benefits of implementing constructability, operability, and maintainability concepts in the construction industry. 145 articles since 1980 up to 2015 have been evaluated using descriptive analysis and quantitative analysis (statistical diagrams). The authors stated that future studies on the subject are needed.

O. Arbabi et al. of Mehralborz Institute of Higher Education and Tehran University (Tehran, Iran) investigate barriers in implementing constructability, operability, and maintainability concepts in infrastructure projects. The authors aim at presenting solutions to overcome existing barriers in implementing COM concepts. The Meta-Synthesis method has been applied for combining and integrating results of literature review. As a result a systematic classification of the solutions to overcome obstacles in implementing the COM concepts in infrastructure projects is presented and discussed.

B. Dastyar et al. of Karaj Payam Noor University (Iran) and Mehralborz Institute of Higher Education (Tehran, Iran) describe the potential of data mining (DM) techniques to develop knowledge management in organizations.
The study presented in the paper is based on a literature review. The most important achievements in the area have been identified and shortly described. The authors concluded that the DM techniques may be effective tools in the development of knowledge management in organizations.

K. Almarri and H. Boussabaine of British University in Dubai (Dubai) investigate the interdependency of value for money (VFM) and ex-post performance indicators of public private partnership projects (PPP). The authors aim to empirically examine the relationship between the PPP project ex-post performance and the value for money creation factors. Over ninety PPP experts from the UK and the UAE participated in this research based on the online questionnaire. Presented research expands the existing knowledge on relationship between the PPP project performance and the VFM creation factors. The study findings have practical implications for the decision makers in local governments and private investors with regard to certain VFM factors that contribute more to the PPP project success.

Z. Kahvandi et al. of Mehralborz Institute of Higher Education (Tehran, Iran) provide an assessment of the research trends in Integrated Project Delivery (IPD) approach of project implementation. In the paper 156 articles from different scientific databases have been analysed. The authors have elaborated a classification of IPD approach through grouping the most important criteria in the construction industry. The main research areas in the field of IPD, research fields and future opportunities have been identified.

The five papers included in this issue present findings mainly based on rich scientific literature review. One hopes that the contents of the presented papers lead to practical implementation of the research ideas and methods presented here.

\section{References}

Alleman, G. B. (2014). Performance-Based Project Management: Increasing the Probability of Project Success. AMACOM, New York. 